\title{
DE VALENCIA A PORTUGAL Y FLANDES RELACIONES DURANTE LA EDAD MEDIA
}

\author{
José Hinojosa Moltavo
}

Durante los siglos medievales la ciudad y reino de Valencia desarrollaron gran parte de su actividad mercantil cara al Mediterráneo, que entonces sí era un auténtico «Mare Nostrum" para cuantos vivían en sus orillas. Aquí labró su prosperidad igual que Cataluña, Mallorca o las repúblicas italianas. Pero el Mediterráneo no dejaba de ser un mar cerrado, casi un lago, y como todas ellas y tan pronto como fue factible buscó ampliar sus horizontes por el oeste, al otro lado de las columnas de Hércules. En esto no fue la primera, ya que se adelantaron los navegantes italianos, catalanes y mallorquines, todos en la segunda mitad del siglo XIII, periodo en el que Valencia concentraba los esfuerzos en su consolidación como reino. Al menos, la documentación conservada no recoge noticias de la posible presencia de valencianos en los paísea atlánticos.

Nos encontramos, además, con un tema totalmente desconocido para la historiografía valenciana, si exceptuamos un trabajo publicado por Felipe MATEU I LLOPIS en el año 1934, donde abordaba las relaciones de Cataluña, Valencia y Mallorca con Inglaterra, preferentemente desde una perspectiva numismática, si bien hay 
alusiones de carácter económico (1). Existen también algunas referencias aisladas al papel de Valencia como escala en la ruta a Flandes en las obras de tipo económico consagradas a Cataluña, pero el conjunto puede calificarse de insignificante, sin que permita tener una visión clara de los contactos que Valencia mantuvo con Portugal y Flandes, objeto del presente trabajo.

Una visión que se centra en la capital del reino, ya que aquí se encuentra la abundante documentación de tipo comercial consultada y que supone un elemento de trabajo indispensable a la hora de estudiar estas relaciones. Sería de gran interés ver que datos podía proporcionar la documentación de Alicante, otra de las escalas junto con Denia y puertos de La Marina, en las rutas atlánticas; con todo creemos que no haría sino ratificar las conclusiones a las que hemos llegado.

\section{1. - VALENGIA Y PORTUGAL}

La inclinación de Valencia hacia los países ribereños del Atlántico se vio favorecida y estimulada por un hecho clave: la apertura del Estrecho de Gibraltar, empresa finalizada a mediados del siglo XIV, pero que ya mucho antes había permitido alcanzar los dos grandes polos comerciales de Occidente: Italia y Flandes. Al mismo tiempo, las excelentes relaciones políticas entre las coronas aragonesa y portuguesa hicieron más fáciles los intercambios mercantiles.

Las noticias más antiguas que se conservan referentes al comercio con Portugal son de 1380 , fecha en la que los jurados de la ciudad protestaron al soberano portugués por haber sido capturadas en sus aguas algunas embarcaciones con mercancías de catalanes y valencianos. El motivo parece que eran ciertas sumas adeudadas por el rey de Aragón al de Portugal, si bien las autoridades valencianas en su carta lo único que les preocupa es la defensa del comercio y la devolución de lo robado (2). Para estas fechas los inter-

(1) Cfr. MATEU I LloPIS, Felipe. Les relacions del Principat de Catalunya i els regnes de Valéncia i Mallorca amb Anglaterra i el paral-lelisme d'aquests països durant els segles XIII, XIV i XV. (Castellón de la Plana, 1934).

(2) Cfr. ARCHIVO HISTORICO MUNICIPAL (en adelante A.H.M.) Letres misives. g3-4. fol. $181 \mathrm{v}-182 \mathrm{r}$. 
cambios estaban ya consolidados, que duda cabe, tal como confirma la abundante documentación contenida en las series del $\mathrm{Ma}$ estre Racional y Bailía del Archivo del Reino de Valencia, si bien presenta el pequeño inconveniente de referirse casi siempre a la exportación de productos prohibidos.

En efecto, a partir de 1381 el número de asientos que se despachan desde la ciudad de Valencia o su puerto (Grao) con destino al reino de Portugal ofrece el siguiente cuadro:

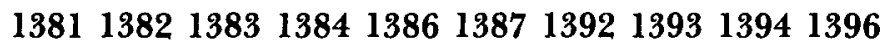

$\begin{array}{lrrrrrrrrrr}\text { Lagos } & 0 & 0 & 0 & 0 & 0 & 0 & 0 & 0 & 0 & 0 \\ \text { Lisboa } & 1 & 0 & 2 & 0 & 0 & 6 & 0 & 0 & 0 & 37 \\ \text { Oporto } & 0 & 0 & 0 & 0 & 0 & 0 & 0 & 0 & 0 & 0 \\ \text { Portugal } & 4 & 1 & 14 & 4 & 0 & 11 & 65 & 36 & 81 & 41 \\ \text { Setuval } & 0 & 0 & 0 & 0 & 0 & 0 & 0 & 0 & 0 & 2 \\ \text { Viana } & 0 & 0 & 0 & 0 & 0 & 0 & 0 & 0 & 0 & 2 \\ \text { TOTAL } & 5 & 1 & 16 & 4 & 0 & 17 & 65 & 36 & 81 & 82\end{array}$

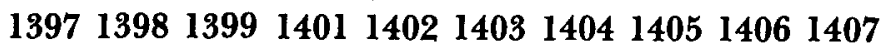

$\begin{array}{lrlrllllrrr}\text { Lagos } & 0 & 0 & 0 & 0 & 0 & 0 & 0 & 0 & 0 & 1 \\ \text { Lisboa } & 12 & 1 & 18 & 0 & 0 & 0 & 9 & 28 & 11 & 20 \\ \text { Oporto } & 0 & 0 & 0 & 0 & 0 & 0 & 0 & 0 & 0 & 0 \\ \text { Portugal } & 19 & 0 & 27 & 0 & 1 & 0 & 64 & 68 & 49 & 39 \\ \text { Setuval } & 0 & 0 & 0 & 0 & 0 & 0 & 0 & 0 & 1 & 2 \\ \text { Viana } & 1 & 0 & 0 & 1 & 3 & 2 & 6 & 0 & 0 & 0 \\ \text { TOTAL } & 32 & 1 & 45 & 1 & 5 & 2 & 79 & 96 & 61 & 62\end{array}$

$1408140914121413 \quad 1414 \quad 1415 \quad 14161417 \quad 14181422$

$\begin{array}{lrrrrrrrrrr}\text { Lagos } & 0 & 0 & 0 & 0 & 0 & 0 & 0 & 0 & 0 & 0 \\ \text { Lisboa } & 1 & 0 & 1 & 11 & 0 & 2 & 1 & 0 & 0 & 0 \\ \text { Oporto } & 0 & 0 & 0 & 0 & 0 & 0 & 0 & 0 & 0 & 0 \\ \text { Portugal } & 7 & 4 & 83 & 53 & 61 & 4 & 55 & 104 & 2 & 24 \\ \text { Setuval } & 0 & 0 & 0 & 0 & 0 & 0 & 0 & 0 & 0 & 0 \\ \text { Viana } & 0 & 0 & 0 & 0 & 0 & 0 & 22 & 0 & 0 & 0 \\ \text { TOTAL } & 8 & 4 & 84 & 64 & 61 & 6 & 78 & 104 & 2 & 24\end{array}$




$\begin{array}{lrrrrrrrrr}\text { Lagos } & 0 & 0 & 0 & 0 & 0 & 0 & 0 & 0 & 0 \\ \text { Lisboa } & 0 & 0 & 2 & 0 & 0 & 0 & 0 & 0 & 0 \\ \text { Oporto } & 0 & 0 & 02 & 0 & 0 & 0 & 0 & 0 & \\ \text { Portugal } & 71 & 4 & 26 & 20 & 46 & 7 & 50 & 54 & 15 \\ \text { Setuval } & 0 & 0 & 0 & 0 & 0 & 0 & 0 & 0 & 0 \\ \text { Viana } & 0 & 0 & 0 & 0 & 0 & 0 & 0 & 0 & 0 \\ \text { TOTAL } & 71 & 4 & 28 & 22 & 46 & 7 & 50 & 54 & 15\end{array}$

Como puede verse unas relaciones que sufren fuertes oscilaciones anuales, sin que aparentemente hubiera motivación alguna, tanto más cuanto que ambos países políticamente estaban en paz. Quizá estas variaciones puedan relacionarse con la oferta y la demanda de mercancías procedentes de Portugal. Si tenemos en cuenta que la pesca constituye la principal importación que Valencia efectuaba del reino portugués, una mayor abundancia de pescado del Mediterráneo o un mal año para la pesca atlántica darían lugar a estas aparentes anomalías. El que las cifras manejadas sean de asientos exportados no varía el panorama, ya que lo habitual es que los envíos hacia el reino luso de hagan en las mismas embarcaciones portuguesas que traían el pescado.

Frente al bajo ritmo mantenido a finales del siglo XIV, ya desde comienzos de la centurias siguiente se percibe una reanimación en los intercambios. Dentro del contexto de los productos vedados la participación portuguesa en la primera década del quince es esta (3):

AÑo TOTAL VIAJES A PORTUGaL PORCENTAJE

$\begin{array}{llrr}1401 & 1987 & 89 & 4,4 \% \\ 1402 & 2083 & 134 & 6,3 \% \\ 1403 & 1521 & 80 & 5,2 \% \\ 1404 & 1192 & 81 & 6,8 \% \\ 1405 & 1175 & 159 & 13,5 \% \\ 1406 & 1081 & 97 & 8,9 \% \\ 1407 & 1159 & 104 & 8,9 \% \\ 1408 & 1123 & 117 & 10,4 \% \\ 1409 & 1023 & 4 & -\end{array}$




$\begin{array}{ccrr}\text { AÑo } & \text { VIAJES POR MAR } & \text { A PORTUGAL } & \text { PORCENT } \\ & & & \\ 1401 & 742 & 89 & 11,9 \% \\ 1402 & 780 & 134 & 17,1 \% \\ 1403 & 646 & 80 & 12,3 \% \\ 1404 & 1134 & 81 & 7 \% \\ 1405 & 625 & 159 & 25,4 \% \\ 1406 & 531 & 97 & 18,1 \% \\ 1407 & 510 & 104 & 20 \% \\ 1408 & 633 & 117 & 18,4 \% \\ 1409 & 290 & 4 & 1 \%\end{array}$

Un porcentaje nada despreciable, especialmente en algunos años como 1405 cuando se alcanzó el $25 \%$ del tráfico marítimo. Los viajes por mar son siempre preferidos a la vía terrestre. Las pocas veces que ésta se utiliza es atravesando el reino de Castilla, con el consiguiente gravamen en peajes que ello representaba para los productos.

Destino de los productos valencianos son los principales puertos portugueses: Lisboa Viana, Oporto, Setuval, Lagos, aunque es difícil establecer una escala de orden al quedar englobados muchos de ellos bajo la simple denominación de Portugal.

Son viajes de carácter claramente estacional, ya que practicamente todos tienen lugar en la primera mitad del año, con preferencias desde febrero a abril. En estas fechas se efectuan la mayoría de las operaciones, detectándose en los meses otoñales la presencia esporádica de algunas naves portuguesas. En 1416, por ejemplo, de 9 embarcaciones despachadas, 7 lo fueron hasta el 30 de marzo (4).

Las embarcaciones más utilizadas son la barca y la nave, preferidas por su tonelaje y su adaptación a los tipos de navegación de cabotaje y atlántica:; tampoco faltan los balleneros, galeras y carabelas en las siguientes cifras:

(3) Cfr. HINOJOSA MONTALVO, José, Valencia y el comercio de exportación durante la primera década del siglo XV (Coses Vedades). Tesis doctoral inédita. (V'alencia. 1972).

(4) Cfr. ARCHIVO DEL REINO DE VALENCIA (A.R.V.) Bailia, 255. 
Barca

$\begin{array}{lll}1405 & 1412 \quad 1413\end{array}$

Ballenero

19

9

5

1414

$1415 \quad 1416$

Caravela

$0 \quad 0$

Laud

$0 \quad 0$

0

8

16

6

Nave

$0 \quad 0$

0

0

$0 \quad 0$

$2 \quad 15$

Galera

$0 \quad 0$

0

0

0

0

0

$0 \quad 3$

2

$0 \quad 0$

$\begin{array}{llllllll}1426 & 1428 & 1429 & 1430 & 1431 & 1432 & 1434 & 1435\end{array}$

Barca

Ballenero

$\begin{array}{ll}2 & 0 \\ 0 & 0 \\ 0 & 0 \\ 0 & 0 \\ 7 & 4 \\ 0 & 0\end{array}$

$\begin{array}{ll}6 & 0 \\ 1 & 0 \\ 0 & 0 \\ 0 & 0 \\ 2 . & 6 \\ 0 & 0\end{array}$

23

$0 \quad 0$

$\begin{array}{ll}5 & 0 \\ 1 & 0 \\ 1 & 3\end{array}$

Caravela

0

$0 \quad 0$

Laud

Nave

Galera

0

0

0

00

3

$2 \quad 11$

0

0

0

Proceden estas embarcaciones de las siguientes localidades:

Barcelona

barca ballenero carabelas galera nave

Bayona

Caminha

Galicia

Genova 1

La Coruña

1

Lisboa

Noya

Oporto

1

Portugal

9

12

San Vicente

de la Barquera

Setuval

Sevilla

Sin especificar

Valencia

1

Venecia

Viana

2

2

3

2

12

Vizcaya

Se trata, pues, de unos intercambios cuyo transporte se realiza en su casi totalidad en embarcaciones de los países atlánticos peninsulares en primer lugar Portugal, y en menor escala castellanos de 
Galicia y de la cornisa cantábrica.

El puerto de Valencia es el centro de una doble ruta en los contactos con Portugal. Por un lado escala de las naves que procedentes del Mediterráneo se dirigen hacia el Atlántico; por otro, terminal de la vía directa entre Portugal y Valencia, la más utilizada. Tras descargar sus mercancías las embarcaciones suelen permanecer en el puerto en período de tiempo que oscilaría entre las dos semanas y algo más de un mes. En 1417, por ejemplo, la barca de Johan Broto de viana estuvo todo el mes de enero y comienzos de febrero en el Grao, realizando en este tiempo 47 operaciones de carga con destino a Portugal (5).

El regreso a Portugal lo hacían bordeando la costa, en una navegación típica de cabotaje. aunque no se citan escalas debieron de utilizarse las de Alicante y los puertos andaluces. A veces, los portugueses tomaban en Valencia flete con destino a las islas Baleares y se convertían en transportistas de valencianos y mallorquines. Precisamente en 1456 tuvo lugar un desagradable suceso protagonizado por una carabela portuguesa que tenía por patrón a Andrés Gallardo. Tras haber cargado con destino a Ibiza, Mallorca y Menorca diversas cantidades de lana, algodón, vino, alpargatas, cuerdas, telas, etc. «induit del spirit diabolical» se marchó del puerto sin esperar a los dueños de las mercancías, quienes clamaban a los jurados de la ciudad de Valencia su devolución (6).

La peligrosidad de los viajes marítimos requería la concesión de guiajes y salvoconductos a patrones y mercaderes por parte de las autoridades reales, concretamente el baile, siempre dispuesto a favorecer el comercio del reino (7). A veces, como contrapartida, se les exige que los productos extraidos de Valencia no vayan a parar a manos de los enemigos del rey de Aragón, concretamente castellanos o italianos.

Estos guiajes se explican en virtud de los riesgos que para la navegación representaban las aguas meridionales de la Península, a causa de la piratería de granadinos y norteafricanos, a los que no dudaban en añadirse los propios portugueses. Los conflictos que esta índole son numerosos. En 1400 los jurados valencianos protestan

(5) Cfr. A.R.V. Bailia, 256.

(6) Cfr. A.H.M. Letres misives. g3-23. fol. 51 v-52 r. 
de la captura de una nave cargada con mercancías de esta ciudad por algunas naves portuguesas, siendo luego conducida a Oporto. Aludcen a «la pau e gran amistança ques entre aqueixs regne e aqueste a l'entremesclat e agradable acolliment de les gents de cascu» y solicitan se devuelva lo robado (8).

Dos años después, en 1402, Johan de Berneda, capitán de tres naves portuguesas apresó en el cabo de San Vicente una vez con mercancías de Ramón Frigola, Vicent Caxa, Vicent Dodena y otros valencianos, enviadas a sus factores Málaga y Sevilla (9). Las autoridades, aunque conscientes del peligro que ello suponía para el comercio no adoptaban medidas severas. Prácticamente se limitaban a protestar ante el monarca portugués. La causa, como ellos mismos reconocen es el enorme gasto que supone armar naves. En 1418 parece que hubo un intento en este sentido pero no prosperó y los incidentes continuaron.

El año 1421 fue particularmente negativo para los mercaderes valencianos, que vieron como una nave que cargó en Sevilla aceite y vino a nombre de Johan Beneyto fue apresada con el pretexto de ser de enemigos (10); o el robo contra la nave de Pere Dartes, mercader

(7) Cfr. Localidades en la sección de Bailía, serie Letres y privilegis (a.R.V.) como ejemplo de guiajes otorgados a portugueses tenemos:

A Ruy Gutierre de Santa Clara, patrón de barca de Portugal, que va del Grao al Cap de Cerver (21-VII-1404).

.. A Alfonso Lourenço, mercader de Elvas, y a Giraldo Rodriguez de Lisboa, que vienen con sus recuas (29-VIII-1424).

- A Loys Alfonso, patrón de nave portugués. (9-X-1424).

- A Johan Vazquez, escudero del infante don Pedro de Portugal, que viene como conseje ro. (15-III-1430).

- A Alfonso Vasquez, patrón de nave de Portugal (25-VIII-1432).

- A Alvaro Stevanes, patrón de nave de Viana (14-II-1432).

- A mossen Pere Vicent, caballero portugués, patrón de una barca y un ballenero (14-X-1434).

- A Alvaro de Flestes, patrón de un ballenero de Lagos y Judas Namies, judío portugués mercader (2-XI-1435).

- Al arzobispo de Lisboa y acompañantes que viene de entrevistarse con la reina para em. barcarse en Valencia (25-I-1437).

- A Johan Alvarez, patrón de ballenero de Lagos (23-II-1437).

- A Alfonso Ianyes, patrón de nave de Oporto (8-VII-1437).

- A Abraffim Valentero, moro vasallo del rey de Portugal, apresado erróneamente en una nave que se creía de genoveses (18-VI-1439).

(8) Cfr. A.H.M. Letres misives. g3-7. Primera mano, sin foliar. 4 agosto, 1400.

(9) Cfr. A.H.M. Letres misives, g3-7. Séptima mano, sin foliar. 20 noviembre 1400.

(10) Cfr. A.H.M. Letres misives, g3-15. Sin foliar. 19 mayo 1421. 
valenciano, que fue atacado cuando salía de Almería rumbo a Orán a cargar trigo por la galera del Palamedes Vasques, llevándose a Ceuta como botín la nave, 3 arrobas de seda, 402 doblas moriscas de oro y otras mercancías (11). Lo más grave no fue el robo sino que el citado mercader tuvo tantos gastos en el pleito sostenido ante las autoridades portuguesas al tratar de recuperar lo robado que acabó por arruinarse, sin que consiguiera que le hicieran justicia (12).

La ocupación de Ceuta por los portugueses hizo de esta plaza una excelente base para la piratería en la zona del Estrecho de Gibraltar, Cartagena, las islas Baleares y el Norte de Africa. En 1433 en el cabo de Palos el ballenero armado de Johan Ianyes de Lisboa capturó la coca valenciana de Johan Anguís que marchaba a Orán (13). Más al sur, en la costa malagueña un ballenero del infante don Enrique, tío del monarca luso, apresó en 1444 a otros castellano que venía a Valencia con pescado y diversas mercancías desde Muros consignadas a varios vecinos de Morvedre. Tras ser robados, la tripulación y los mercaderes fueron arrojados a tierra semidesnudos. Al igual que otras veces Ceuta fue el lugar de refugio de los piratas. Parece, sin embargo, que esta vez la justicia portuguesa fue algo más eficaz y alguno de los damnificados por el robo, como Pero Loppez Verdu de Morvedre, fueron indemnizados. Pero al no hacerse efectiva la sentencia, los jurados de Valencia hubieron de recurrir al rey (14).

La piratería era por estas fechas un fenómeno general en todos los mares y los portugueses no eran la excepción. Como tampoco lo eran los súbditos del monarca aragonés. A veces eran los propios piratas portugueses los vencidos, como le sucedió en 1435 a un ballenero de esta nacionalidad, que después de haber apresado algunas barcas que se dirigían con trigo y "robes" a Valencia, se encontró con la galera del doncel Gilabert de Lupia, siendo vencido y conducido al embarcadero de Elche (15). Otra vez, en 1450 fue una nave que viniendo de Lisboa con diversas mercancías y peregrinos que

(11) Cfr. A.H.M. Letres misives, g3-15. Sin foliar. 23 julio 1421 11 abril 1421.

(12) Cfr. A.H.M. Letres misives, g3-16. Sin foliar. 1 octubre 1422.

(13) Cfr. A.R.V. Letres y privilegis, Bailia, 1147. fol. 467 v

(14) Cfr. A.R.V. Letres y privilegis, Bailia, 1149. fol. $170 \mathrm{r}-\mathrm{r}$.

(15) Cfr. A.H.M. Letres misives, g3-19. Sin foliar, 23 noviembre 1439 
iban a Roma a ganar el jubileo fue apresada por las naves de mossên Pere Ramón Cafortea y Rodrigo de Sent Marti, de Mallorca. Los asaltantes reclamaron a los jurados de Valencia, quienes se justificaron no poder hacer nada en su favor, al ser los asaltantes mallorquines. Se muestran, no obstante, dispuestos a intervenir en su favor ante el rey, pidiendo al mismo tiempo que no se ejerzan represalias contra Jacme Modrinyo, Agosti Nadal, Estheve Batalla y Johan Sollit, pelaires valencianos que en aquel momento se encontraban en Portugal. Temor justificado, por cuanto que a pesar de haber sido guiados por el rey de Portugal sus bienos fueron secuestrados (16).

A pesar de estos peligros, las buenas relaciones entre Portugal y Valencia no se empañaron. Como prueba de ello en 1462 el gobernador general del reino a instancias de los jurados municipales, ratificó el guiaje general que los fueros de Valencia otorgaban a los portugueses que vinieran con pescado y productos alimenticios (17). Protección que será confirmada nuevamente un año después por el soberano aragonés.

¿En qué se apoyaban los intercambios entre Valencia y Portugal? La exportación valenciana tiene como base los artículos manufacturados, aunque no faltan los productos del agro, como alguna partida de almendras, pasas y sobre todo arroz.

Los productos objeto de mayor demanda son la pez, elementos de mobiliario (cofres de diversos tamaños), calderas de cobre, cáña mo, en bruto o elaborado, y las armas de todo tipo desde espadas y lanzas a piezas de armaduras, muchas de ellas propiedad de particulares que las traían a Valencia a reparar. Elaborados muchos de estos productos en Valencia, en otros casos la ciudad actuaba como centro reexportador; en 1422 vemos a Gabriel Torres, ballestero de Mallorca, embarcar en el Grao 140 ballestas mallorquinas rumbo a Portugal; o en 1430 Baltasar Negre envía hilo de alambre, posiblemente importado de Lombardía de donde procedía el citado mercader.

En menor escala encontramos diversidad de mercancías: plomo,

(16) Cfr. A.H.M. Letres misives, g3-21. Sin foliar, 3 julio 1450. 15 septiembre 1450. 28 septiembre 1450 .

(17) Cfr. A.H.M. Letres misives, g3-25. fol. 135 v-136 r. 
utensilios para el ganado, domésticos (copas, saleros, tijeras, alfileres...) herramientas, vajillas de plata, sin que falten los confites y el vino de Morvedre, famoso por aquellas fechas.

A cambio Portugal es la gran proveedora de cueros y pescado: merluza, sardina, atún, bonito, congrio. Otros artículos son castañas, trigo, queso, madera, azúcar de Madera y esclavos, siempre en pequeñas cantidades.

Aunque no hay cifras seguras sobre la balanza comercial entre ambos países cabe suponer que resultaban positiva para el reino de Valencia al ser superior el valor de las manufacturas exportadas a los productos del sector primario importados de Portugal. De cualquier modo no hay que perder de vista que las cantidades embarcadas son en general reducidas y el volumen del tráfico está lejos de alcanzar los niveles mantenidos en los intercambios con los países mediterráneos.

Hay que reseñar igualmente la presencia de pasajeros que embarcan de regreso a Portugal. Mercaderes en su mayoría su ritmo es inestable como muestra el ejemplo de los siguientes años:

$\begin{array}{lrrrrr} & 1405 & 1412 & 1413 & 1414 & 1415 \\ \text { Cristianos } & 16 & 3 & 3 & 0 & 5 \\ \text { Judios } & 1 & 8 & 0 & 8 & 0\end{array}$

Los intercambios están controlados fundamentalmente por mercaderes portugueses (de Oporto, Viana, Lisboa, Setuval, Sintra, etc.), entre los que se detecta una activa minoría de hebreos. En menor cuantía aparecen valencianos, lombardos, mallorquines y algún vizcaino. Las buenas relaciones a veces se empañaban por las marcas ejercidas contra súbditos del otro país. En 1401 los mercaderes valencianos en Portugal se vieron perjudicados en sus negocios. En respuesta las autoridades del reino hicieron marcas contra los portugueses que venían a Valencia, a lo que protestaban los jurados de la ciudad alegando que, ya que traen vituallas deben de ser asegurados, además, según fuero aquellas estaban prescritas y suponían un peligro para los valencianos que navegaban a Portugal y Flandes (18). El malestar subsistió y en 1403 una nueva misiva al

(18) Cfr. A.H.M, Letres misives, g3-7. Sin foliar, 14 febrero 1401. 
soberano portugués pedía el desembargo de los bienes de valencianos retenidos injustamente.

Meses más tarde tenía lugar un incidente similar pero en tierras valencianas. En febrero de 1409 fueron retenidas en el Grao de Valencia dos barcas lusitanas procedentes de Barcelona y luego marcadas por el baile a instancias de $\mathrm{Na}$ Bernadona, mujer de mossén Jacme Centelles, basándose en que poseían derechoa de marca contra los súbditos del rey de Portugal. La queja de los "consellers» barceloneses ante el baile fue inútil, por cuanto que éste no podía intervenir ante una concesión real de ese tipo (20).

En resumen, intercambios regulares aunque con altibajos, productos del sector primario a cambio de manufacturas y control por los marinos y mercaderes lusos.

\section{2. - VALENCIA Y FLANDES}

Flandes e Inglaterra constituyen el límite septentrional alcanzado por navegantes y productos valencianos. Aunque su actividad fue más reducida que la de los catalanes, el grupo más numeroso de los súbditos del rey de Aragón en estos territorios, ya desde fecha temprana aparecen valencianos en Flandes. En 1334 el almirante Ramón de Peralta apresó una nave cargada de alumbre, que procedente de Mesina se dirigía a Flandes consignada por la compañía florentina de los Bardi, bajo la excusa de ser aliados de los genoveses. Esta acción motivó una reclamación por parte del conde de Flandes a los jurados de Valencia acusados de participar en el robo con una coca de la ciudad, amenazando con ejercer represalias contra los súbditos valencianos en sus tierras. Aquellos se defienden alegando que no tienen nada que ver con dicho suceso y piden que se protega a los valencianos "en tal manera que per aquesta rao vehins nostres no reeben alcun dapnatge en lo dic comdat" (21)

Carcemos por completo de cualquier indicación, incluso aproximada, sobre el número de valencianos en Flandes, localizados en Brujas, centro de la actividad para los mercaderes mediterráneos. En octubre de 1413 los jurados solicitan de Johan de Penyaranda y

(20) Cfr. A.R.V. Letres y privilegis, Bailia, 1444. fol. $257 \mathrm{r}$-v.

(21) Cfr. A.H.M. Letres misives, g3. J. fol. $68 \mathrm{r} ; 73 \mathrm{v} ; 74 \mathrm{v} ; 75 \mathrm{R}$. 
Miquel de Vilagines, mercaderes de Valencia en dicha ciudad, el envío urgente de 300 cahices de trigo para poder paliar el déficit existente (22).

Parece que la situación de los valencianos en aquellas tierras atravesó algunos momentos difíciles, al igual que les sucedió a los demás extranjeros. Es una consecuencia de la situación general de la ciudad de Brujas en el siglo XV, y aunque la urbe sigue siendo uno de los emporios mercantiles de Occidente, la crisis se deja sentir y da lugar a la adopción de medidas proteccionistas por las autoridades en defensa de los intereses locales. Ya en febrero de 1405 los cónsules y mercaderes catalanes en Flandes notificaron a sus colegas barceloneses la imposición de un gravoso reglamento a los comerciantes extranjeros en Brujas que restringía su actividad. Se solicitaba que el rey y las ciudades de Barcelona, Valencia y Mallorca escribieran a la condesa de Flandes y a las villas de Gante, Brujas, e Ypres a fin de volver a la anterior situación (23).

No debió de ser fácil resolver el problema, ya que nuévamente en 1419 llegó a manos de los jurados de Valencia las quejas de sus conciudadanos en Brujas ante la prohibición de ejercer la mercadería en dicha ciudad (24). Las vejaciones y detenciones a mercaderes valencianos continuaban a mediados de siglo, protestando la ciudad de la inobservancia de los salvoconductos concedidos (25).

Ello no impidió que se mantuvieran unos contactos más o menos regulares entre ambos territorios, como puede verse a continuación:

\section{NUMERO DE ASISTENTES A FLANDES}

1382: $1 ; 1382: 0 ; 1384: 0 ; 1386: 1 ; 1387: 0 ; 1392: 2 ; 1393: 3$; 1394: 7 ; 1396: 2 ; 1397: 3 ; 1398: 3 ; 1399: 2 ; 1401: 0 ; 1402: 1 1403: 0 ; 1404: 3; 1405: 0; 1406: $0 ; 1407: 2 ; .1408: 0 ; 1409: 1 ; 1412: 7$; 1413: 57 ; 1414: 25 ; 1415: 2 ; 1416: 4; 1417: 3 ; 1422: 3 ; 1426: 6 ; 1428: 6 ; 1430: 3 ; 1431: 5 ; 1432: 21 ; 1434: 6 .

(22) Cfr. A.H.M. Letres misives, g3-12. fol. $64 \mathrm{r}$.

(23) Cfr. CAPMANY Y DE MONTPALAU, Antonio. Memorias históricas sobre la Marina, Comercio y Artes de la antigua ciudad de Barcelona. Madrid. 1779. Tomo 2011. pág. 205. documento CXXII.

(24) Cfr. A.H.M. Letres misives, g3 14 . fol. $149 \mathrm{~V} \cdot 150 \mathrm{r}$.

(25) Cfr. A.H.M. Letres misives, g8-22. Sin foliar. 12 junio 1454. 
Salvo la anomalía de los años 1413,1414 y 1434, rara vez se sobrepasa la media docena de asientos, dando la impresión de tratarse de unas relaciones muy fragmentarias, como verenos al hablar de los navíos o los productos. En los años en los que se conservan datos, las embarcaciones que parten del Grao de Valencia hacia Flandes son:

\section{2}

$\begin{array}{lllllllll}\text { nave } & 4 & 3 & 3 & 5 & 3 & 3 & 1 & 8 \\ \text { galera } & 0 & 0 & 0 & 1 & 1 & 0 & 0 & 2 \\ \text { barca } & 0 & 0 & 0 & 0 & 0 & 0 & 0 & 1\end{array}$

Podía aducirse que la documentación consultada es limitada en su alcance, pero si comprobamos otras fuentes como son los protocolos notariales donde constan los contratos de flete vemos que no por ello las cifras aumentan. En 1476, por ejemplo, en los protocolos de Jaime Salvador, notario especialista en asuntos mercantiles sólo aparece un viaje a Flandes, y tres en 1493 (26). Así pues, pocos viajes con destino a Flandes.

Las embarcaciones empleadas son la nave y la galera, imprescindibles para la navegación de altura. Proceden las naves de Génova (8), Vizcaya (8), Barcelona (3), Galicia (2), Portugal (2), Bilbao (1), Copliure (1), Mallorca (1), Muros (1), Pisa (1). El transporte, pues, está en manos de genoveses y vizcainos. Los italianos utilizan el Grao valenciano como escala en la ruta Italia-Flandes, en tanto que la presencia de los vascos corrobora la intensa penetración de los castellanos en el área occidental del Mediterráneo durante el siglo $\mathrm{XV}$ y su papel como transportistas a cuenta de los mercaderes de la Corona de Aragón. Al igual que veíamos en las relaciones con Portugal también aquí el papel de la marina mercante valenciana es insignificante, y no por falta de embarcaciones idoneas, ya que naves y galeras las vemos surcando las rutas italianas, norteafricanas o de las Islas, cuya menor rentabilidad las haría probablemente preferibles a las atlánticas. La escala de las galeras barcelonesas en Valencia rumbo a Flandes coincide, como señaló Claude Carrere,

(26) Cfr. A.R.V. Protocolos, 1996 y 2010. 
con el establecimiento en 1430 por parte de la Generalidad catalana de una línea regular de Barcelona a Flandes, a imitación de las venecianas (27). Tendrán como patrones a miembros de la familia Sirvent, especialistas en este tipo de navíos.

No todos los embarques se hacían en el Grao; a veces se utilizaban los puertos de Cullera, Gandía, Jávea, Villajoyosa y, sobre todo, Denia y Alicante, donde cargan abundantes frutos secos y productos agrarios: arroz, azúcar, uvas, vino. Desde aquí es normal que se dirigan a Cádiz antes de dar el salto definitivo hacia la Europa del Norte. Puertos de destino son La Esclusa, Midelbourg, Roomer Swaal y Flandes en general.

También hay que citar la presencia de las galeras florentinas y venecianas que a su regreso de los Países Bajos tocan en Valencia, y el posible intento por parte valenciana de establecer una línea regular de galeras con Flandes. Si esto fuera cierto sería anterior a la de Barcelona. En efecto, en marzo de 1426 el baile general del reino comunica a su lugarteniente en Denia haberle sido otorgada licencia a Christofol Spindoli, mercader alemán a la sazón negociante en Valencia, para poder cargar en la nave del portugués Loys Johan que iba a Flandes 25 costales de almendras, a pesar de existir una orden prohibiendo que no se carguen mercancías para Flandes en ningún navío en tanto que la galera de mercadería de Anthoni d'Alagó, de Valencia, que viene de Flandes sea despachada nuevamente con dicho destino (28). Si estas medidas proteccionistas sirvieron para consolidar esta línea marítima es algo que la documentación dejó en suspenso.

(27) Cfr. CARRERE, Claude. Barcelona, centre économique. 1380 1462. (Paris, 1967) pág. 276.

(28) Cfr. A.R.V. Letres y privilegis, Bailía, 1146. fol. 368 r.

(29) Cfr. Algunos de los guiajes concedidos en estos años son:

- A la galera de mercadería florentina de Prior Mareto, que viene a Valencia y luego va a Flandes (3-VI-1430).

- A Carlo Italia, patrón de nave de Geneva, que viene de Flandes (2-IX-1431).

- A Joffre Servent de Barcelona, patrón de galera de mercadería (23-X-1436).

- A Joffre Servent y Francesch de Casasatia, patrones de dos galeras barceloneses que vienen de Flandes (23-IV-1437).

- A Salvi Nayro, Jacobo Cadaldi y Bartholome Caponi, patrones de dos galeras florentinas que vienen de Pisa y van a Flandes (agosto 1438).

- A Loys Servent y Felip de Ferreres, patrones de 2 galeras barcelonesas que vienen de Flandes (25-VII-1439).

- A Jacobo Ysnardo, patrón de nave que viene de Pisa y va a Flandes (30-VII-1448). 
También al igual que vimos con Portugal se conceden salvoconductos para ir a Flandes (29), dada la peligrosidad del viaje. Los tres principales enemigos de los mercaderes que comerciaban con el mar del Norte eran los piratas berberiscos, portugueses y castellanos. A veces fallaban en su intento de captura, como sucedió a 1393 en aguas ceutíes con una nave que venía de Flandes a Valencia (30). Ya antes aludimos al robo perpetrado por algunas naves portuguesas en agosto de 1400 a una nave que con mercancías valencianas hacía la vía de Flandes (31).

Pero los más peligrosos fueron siempre los castellanos, y los ataques solian producirse en aguas gallegas o del golfo de Vizcaya. Podía suceder que fuera el mismo monarca de Castilla quien procediera contra los valencianos, que es lo que sucedió en 1380 al ser detenida en el puerto de La Coruña la nave de Castro Urdiales, que patroneaba Diego Fernández de les Cortines, en ruta a Flandes con productos valencianos. La razón alegada fue la imperiosa necesidad de naves que tenía el rey para formar una armada (32). Eran años de guerra entre los reinos del occidente peninsular y no era raro que resultaran perjudicados quienes nada tenían que ver en el conflicto.

En ocasiones el perjuicio afectaba al capítulo de los impuestos, como sabemos por la queja que los jurados de Valencia hacen en 1394 ante el rey de Castilla, basándose en ser contrario a los capítulos de la quema estipulados entre ambos reinos los derechos que los "quemers" cobran en los mares castellanos a las mercancías enviadas a Flandes (33).

Otro incidente grave se produjo en 1423. Algunos mercaderes de Valencia fueron informados que sus factores en Flandes habían cargado diversos artículos en una nave que partía de La Esclusa. A su patrón, el vizcaino Lope Lopez de Seraus, le fue jugada una mala pasada - ignoramos en qué consistió - por los flamencos, y pensando que las mercancías que llevaban eran de estos se las llevan a Gomaya (¿Zumaya?) donde las descargó. Los jurados de la ciudad consideraban totalmente injusto aquel proceder, ya que si el patrồn

(30) Cfr. A.H.M. Letres misives, g3-5. fol. $120 \mathrm{r}$.

(31) Cfr. A.H.M. Letres misives, g3-7. Sin foliar. 4 agosto 1400.

(32) Cfr. A.H.M. Letres misives, g3-4. fol. 162 r.

(33) Cfr. A.H.M. Letres misives, g3-5. fol. 256 r. 8 mayo 1394. 
tenían alguna queja contra los flamencos no por ello iban a pagarlo los valencianos, porque igual se podía hacer en Valencia con los vizcainos «qui fort soven arriben en aquestes parts ab ferre e altres mercaderies", y, tras enumerar los productos secuestrados, - entre los que se incluía una imagen consignada a Johan Ferrer de Valencia - pedían su devolución (34).

Valencia envía a las ciudades flamencas productos del agro, sobre todo arroz (en 1432, el año mejor documentado, salen 939 costales, 10 arrobas y 3 quintales delacitada graminea) y frutos secos (almendras, pasas...), confites, piñones, aceite, azucar en panes o en polvo, cáñamo, vino, melaza y algunas manufacturas de madera (cofres) o metal (armas, destacando las poezas para ballesta y armaduras), pero siempre en reducidas cantidades. Ello hacía que el comercio con Flandes fuera deficitario para Valencia, donde las naves y galeras descargaban trigo, "robes e pelleria», tapicería, telas de Brabante. Holanda o Alemania, relojes, hilo de latón, hoja de hierro, imágenes, pescado, mercería, vidrio, hilo de ballesta, hoja de latón y de estaño, clavos, cobre, plomo, estaño, fustanes, bonetes, espejos, etc... Parte de estos productos se quedan en Valencia y el resto se envían bien a tierras del interior, bien a Barcelona (35).

Es un comercio en manos de mercaderes flamencos, alemanes, italianos y valencianos. En un reciente trabajo aludíamos a la escasa presencia de mercaderes flamencos en Valencia (36), recogiendo tan solo el guiaje otorgado por la reina doña Juana en 1469 a Girart Xlumey y Fat de la Straga, mercaderes de Brujas que vienen a Valencia. Hoy, sin embargo, poseemos algunos datos más y de mayor antigüedad. En 1416 se documenta un tal Johan de Cortrays, Anrich de Flandez y Francesch de Ipre (37); en 1426, Johan de Ribera, mercader de Flandes, y Goli de Cortray (38); en 1428, Arnau

(34) Cfr. A.H.M. Letres misives, g3-16. Sin foliar. 2 marzo 1423. 15 abril, 6 julio.

(35) Cfr. A.R.V. Bailia, 263. fol. 187, primera mano. Se llevan estaño que trae la galera florentina de Pere Campi.

(36) Cfr. HINOJOSA MONTALVO, José. Mercaderes extrapeninsulares en la Valencia del siglo XV. en Saitabi, XXVI. (Valencia, 1976).

(37) Cfr. GIMENO CANOVAS, $M^{\text {a }}$ del Carmen. Transacciones de "Coses vedades» en 1450. Tesis de licenciatura inédita. Valencia, 1973.

(38) Cfr. A.R.V. Bailia, 262. fol. 243 r. 292 v. 
de Guant (39); en 1459, Rolan, flamenco. La única mención de una embarcación de Flandes es de 1425, cuando el baile general da instrucciones a sus oficiales a fin de que no molesten a la nave de Miquel Barut de Brujas, que va a Sicilia a cargar trigo y otros alimentos con destino a Valencia (40).

La presencia germana comienza a ser importante a partir de 1430. Ya ese año vemos a Abel de Colunya enviando arroz a Flandes. A él se añadieron en los años siguientes en esta ruta Jordi Ranc, Anrich Constança, y Jous Ompis (41). Recordemos que los Ompis (Hompis, Humpis) serán los más destacados agentes de la Gran Compañía de Ravensburgo en la ciudad del Turia. En 1448 Noffre Ompis «de la gran companyia» importaba artículos de los Paises Bajos. (42).

Parece, sin embargo, que el grueso de las transacciones pasaba por manos italianas. Baste como ejemplo el año 1432, uno de los más activos en los envíos a Flandes gracias a la liberalización de las exportaciones de arroz. Ese año participan en el comercio con Flandes Jacobo Verni, Lorenco Romani, Leonardo Frescobaldi, Girardo Sent Filaci, Paulo Saltaretli y Thomas Feu,florentinos; Apolloni Bossay, pisano; Loys de Nayro, Rafel Catani, Aduart Italia y Agosti de Fornar, genoveses (43). La tradición se mantendrá y a finales de la centura, en 1493, pueden verse a menudo fletes de italianos hacia Flandes. En 1493 Bernardo de Franquis y hermanos, Bernardo Puello, Christofol Calvo y otros genoveses fletaron la nave de Martín Gavilán de Laredo, surta en Denia, para que fuera a Flandes. Y lo mismo hacen Jacobo Spanochi, sienés residente en Valen. cia y procurador de los herederos de micer Ambrosi Spanochi y Compañía con la nave de Johan de Sent Johan, de Zumaya (44).

En cuanto a los valencianos que se relacionan con Flandes dentro del grupo de los mercaderes forman un apartado muy interesante

(39) Cfr. A.R.V. Bailía, 264.

(40) Cfr. A.R.V. Letres y privilegis, Bailía. 1146. fol. 301. $\mathrm{r}$.

(41) Cfr. Aloys SCHULTE en su obra Geschichte der grosen Ravensburger Handelsgesellochaft, 3 vol. (Wiesbaden, 1964) anotaba la presencia en Valencia de Ubel de Cologne (Abel de Colunya) en 1434 como la primera mención de un alemán en dicha urbe. En reali. dad mercaderes alemanes aparecen ya en el primer cuarto del siglo XV, aunque no comercian con los países atlánticos. Su número es, por supuesto, muy reducido.

(42) Cfr. A.R.V. Bailía, apéndice 68.

(43) Cfr. A.R.V. Bailía, 269. 
los conversos, cuyo comercio con la Europa del Norte ha sido recientemente estudiado por Jacqueline Guiral a partir de los protocolos del notario Jaime Salvador (45). Resumiendo sus conclusiones tenemos: desde 1476 a 1501 se llevan a cabo 38 contratos de flete con destino al Atlántico Norte, de ellos 32 a Flandes. Productos y destinos son los ya conocidos. Parece que no hubo mercaderes conversos especializados en su ruta comercial, quizá el más regular sea Francesch Bertran, cuyo hermano Nicolau es corresponsal en Brujas. Elasticidad en los contratos con el fin de adaptarse a las leyes de la oferta y de la demanda.

Por último, y dentro del área atlántica, hacer una breve alusión a los contactos comerciales con INGLATERRA, tanto en la isla como en sus posesiones continentales. La noticia más vieja es de 1334 y da cuenta del envío de «draps franceses» desde Bayona a Valencia, vía Zaragoza (46). Todavía el Estrecho de Gibraltar sigue siendo peligroso y lo normal era utilizar la vía terrestre. L'os negocios de los mercaderes valencianos en Gascuña quedarán centralizados en las plazas de Bayona y Burdeos. Su volumen sería reducido. Los mismos jurados de Valencia en 1394 quejándose al marqués de Villena por las medidas represivas del monarca inglés a causa de ciertas deudas contraidas por el hijo de aquel el conde de Denia dicen: «car sapia vostra senyoria que be que nostres pochs mercaders de nostra nacio facen mercaderia en terra de bordaleses, em-

(44) Cfr. GUIRAL, Jacqueline. Convers á Valence á la fin du XV' siècle. en Melanges de la Casa de Velázquez (Madrid. 1975). XI. págs. 81-98. Los fletes hechos para la Furopa del Norte por los conversos en este periodo son:

$\begin{array}{lrrrrrrrrrrr} & 1476 & 1477 & 1478 & 1479 & 1481 & 1482 & 1484 & 1485 & 1488 & 1489 & 1490 \\ \text { Flandes } & 0 & 1 & 0 & 1 & 1 & 3 & 0 & 0 & 2 & 0 & 0 \\ \text { Inglaterra } & 0 & 0 & 0 & 0 & 1 & 0 & 0 & 0 & 0 & 0 & 0 \\ \text { Bretaña } & 0 & 0 & 0 & 0 & 1 & 0 & 0 & 0 & 0 & 0 & 0 \\ \text { Rouen } & 0 & 0 & 0 & 0 & 0 & 0 & 0 & 0 & 0 & 0 & 0 \\ \text { Lisboa } & 0 & 0 & 0 & 0 & 0 & 0 & 0 & 0 & 0 & 0 & 0 \\ & 1491 & 1492 & 1493 & 1494 & 1495 & 1496 & 1497 & 1498 & 1499 & 1500 & 1501 \\ \text { Flandes } & 2 & 0 & 1 & 0 & 2 & 1 & 5 & 2 & 3 & 2 & 6 \\ \text { Inglaterra } & 0 & 0 & 1 & 0 & 0 & 1 & 0 & 0 & 0 & 0 & 0 \\ \text { Bretaña } & 0 & 0 & 1 & 0 & 0 & 0 & 0 & 0 & 0 & 0 & 0 \\ \text { Rouen } & 1 & 0 & 0 & 0 & 0 & 0 & 0 & 0 & 0 & 1 & 0 \\ \text { Lisboa } & 0 & 0 & 0 & 0 & 0 & 0 & 0 & 0 & 0 & 1 & 0\end{array}$

(45) Cfr. A.H.M. Letres misives, g3-1. fol $17 \mathrm{r}$.

(46) Cfr. A.H.M. Letres misives, g3-5. fol. 255 v 
pero molta la fan en Flandes, per la qual les cove arribar en la costa de Bayona e de Bordeu e de la ylla d'Anglaterra»

Con las islas los contactos comerciales se iniciaron a fines del siglo XIII como confirman los privilegios de Eduardo II a los catalanes. No olvidemos que catalanes y valencianos a menudo participan juntos en estas transacciones, citándose tan solo a los primeros. Pero los intercambios valencianos se mantuvieron siempre a un nivel inferior al de los mercaderes del Principado y más bien pueden calificarse de esporádicos. Se exportarían productos similares a los de Flandes, importando Valencia lanas, cueros y plomo. 